\title{
Significant reproductive skew in the facultatively polygynous ant Pheidole pallidula
}

\author{
D. FOURNIER, ${ }^{*}$ S. ARON* and L. KELLER† \\ *Behavioural and Evolutionary Ecology CP 160/12, Université Libre de Bruxelles, Avenue F.D. Roosevelt, 50, B-1050 Brussels, \\ Belgium, +Department of Ecology and Evolution, University of Lausanne, Bâtiment de Biologie, CH-1015 Lausanne, Switzerland
}

\begin{abstract}
Reproductive skew - the extent to which reproduction is unevenly shared between individuals in a social group - varies greatly between and within animal species. In this study, we investigated how queens share parentage in polygynous (multiple queen) colonies of the Mediterranean ant Pheidole pallidula. We used highly polymorphic microsatellites markers to determine parentage of gynes (new queens), males and workers in P. pallidula field colonies. The comparison of the genotypes of young and adult workers revealed a very low queen turnover (less than 2\%). The first main finding of the study of reproductive skew in these colonies was that there was a significant departure from equal contribution of queens to gyne, male and worker production. Reproductive skew was greater for male production than for queen and worker production. There was no relationship between the magnitude of the reproductive skew and the number of reproductive queens per colony, their relatedness and the overall colony productivity, some of the factors predicted to influence the extent of reproductive skew. Finally, our study revealed for the first time a tradeoff in the relative contribution of nestmate queens to gyne and worker production. The queens contributing more to gyne production contributed significantly less to worker production.
\end{abstract}

Keywords: ants, kin selection, polygyny, queen replacement, reproductive conflict, reproductive skew

Received 6 June 2003; revision received 26 August 2003; accepted 3 October 2003

\section{Introduction}

There is considerable intra- and interspecific variation in how individuals in a group share reproduction. A central question in studies of social evolution is to identify factors responsible for these differences in apportionment of reproduction (Keller \& Reeve 1994). A shorthand term to describe the distribution of direct reproduction among individuals is reproductive skew (Keller \& Reeve 1994). In high-skew societies, actual direct reproduction is concentrated in one or a small subset of individuals in the group, whereas in low-skew societies reproduction is distributed more evenly among group members.

Built on kin selection theory, a new conceptual framework has been developed recently to determine how ecological, genetic and social factors influence jointly group

Correspondence: Denis Fournier. Fax: + 32 (0) 265024 45; E-mail: Denis.Fournier@ulb.ac.be stability and reproductive skew among group members (Emlen 1982a,b; Vehrencamp 1983a,b; Reeve \& Ratnieks 1993; Keller \& Reeve 1994; Reeve \& Keller 1995; Reeve et al. 1998; Johnstone \& Cant 1999; Johnstone 2000; Reeve \& Keller 2001). In essence, skew models delineate the possible reproductive strategies available to a focal individual. They define under what conditions an individual should cooperate and / or sacrifice part or all of its direct offspring production rather than leaving the group to breed independently. The three main parameters important in skew models are: (1) the expected success of a subordinate that reproduces solitarily; (2) the group's overall productivity if the subordinate co-operates in group breeding; and (3) the genetic relatedness among group members. The effect of these parameters on reproductive skew is expected to vary depending on which group member has control over reproductive skew. Over the last two decades, a considerable amount of effort has been devoted to developing reproductive skew models (Vehrencamp 1983a,b; Reeve \& 
Ratnieks 1993; Keller \& Reeve 1994; Reeve \& Keller 1997; Reeve 1998; Reeve et al. 1998; Johnstone \& Cant 1999; Ragsdale 1999; Johnstone 2000; Reeve \& Emlen 2000). However, this profusion of models contrasts with the paucity of studies testing their assumptions and predictions (Reeve \& Keller 2001)

Most of the studies that have attempted to determine how variation in relatedness and ecological factors influence skew within species have been conducted in social insects, ants and wasps in particular (Bourke \& Heinze 1994; Bourke et al. 1997; Reeve et al. 2000; Reeve \& Keller 2001; Rüppell et al. 2002). A particular feature of these social Hymenoptera is that there are two types of females within colonies; queens that carry out most or all the reproduction and workers that perform most of the other tasks, including foraging, nest construction and brood care. Colonies can contain one (monogyny) or several queens (polygyny) (Keller 1993b).

In polygynous colonies there is considerable intra- and interspecific variation in the apportionment of maternity. Several studies have shown significant reproductive skew for worker and gyne (new winged queen) parentage (Ross 1988; Seppä 1994; Bourke et al. 1997; Hannonen \& Sundström 2002). Differences in maternity may arise from several factors, including differences between queens in their fecundity, proportion of eggs developing to adulthood and likelihood of female eggs to develop into gynes or workers (Keller 1993a). In Formica fusca there are significant differences between queens in their eggs' likelihood to develop into adults, and brood viability is highest for queens that are on average most related to workers (Hannonen \& Sundström 2003). The authors suggested that this is because workers exhibit nepotism by rearing a greater proportion of eggs laid by the queen to which they are most closely related on average. However, there is a simpler and more probable explanation, namely that the queens which produce more viable eggs have the highest maternity and thus are also more related to workers on average. Thus, the observed pattern may be explained without invoking nepotism, a process that seems to be absent within colonies of social insects (Keller 1997).

Only few studies have determined skew for male parentage (Fournier \& Keller 2001; Heinze et al. 2001). Another important aspect that has also received little attention is whether there are trade-offs in the relative contribution of queens to male, gyne and worker production. This is an important issue because in most ant species workers rarely, if ever, reproduce.

In this study, we describe the results of a detailed investigation of reproductive skew in the ant Pheidole pallidula. This species is facultatively polygynous with colonies containing from one to few queens which are typically unrelated (Fournier et al. 2002; Fournier et al. 2003). An interesting aspect of this species is that queens are apparently able to influence the fate of female eggs. Studies in laboratory colonies containing a single queen suggested that eggs develop either into reproductive females or workers, depending on the juvenile hormone and ecdysterone levels of queens (Passera 1980; Suzzoni et al. 1980; Passera 1982). However, it is unknown whether these maternal effects on caste determination translate into differences in apportionment of female sexuals, workers and males in polygynous colonies.

We used highly polymorphic markers to determine parentage of gynes, males and workers in P. pallidula field colonies. We also examined the factors that may potentially influence unequal reproduction in polygynous colonies. First, because estimates of reproductive skew are directly affected by queen turnover (Heinze \& Keller 2000), we estimated the rate of queen replacement in the population studied. Second, we tested for a relationship between the number of queens and the magnitude of reproductive skew. Third, we examined whether reproductive skew is associated with the relatedness of breeders, number of breeders and overall colony productivity. Finally, we determined whether there were trade-offs in the relative contribution of nestmate queens to male, gyne and worker production.

\section{Materials and methods}

\section{Field collection and sampling}

Queens of P. pallidula mate only once and mating occurs between unrelated individuals (Fournier et al. 2002). Workers are completely sterile, with all eggs in a colony being laid by the queen(s) (Passera 1978). In this species, there is no overwintering brood (Passera 1980). Queens lay eggs from early March to early September. Eggs laid early in spring give rise to male and female sexuals that emerge at the end of June/early July. The eggs laid develop later into workers (i.e. minors and soldiers), most of them emerging after the sexual brood (Bontpart 1964). Sex allocation is associated closely with the breeding structure, with monogynous colonies producing a male-biased sex ratio investment and polygynous colonies producing almost all female sexuals (Fournier et al. 2003). Because of the very small number of males produced in polygynous colonies, the estimate of reproductive skew for male production is less accurate than the estimates for gyne and worker production.

$P$. pallidula colonies were sampled just before mating flights on 29 June and 1 July 1999 from a facultatively polygynous population located in Bruniquel (Tarn-etGaronne, France). Colonies of this species extend underground on rocky soil so that complete excavation and collection of the queens that are located in the deepest part of the nest in summer was not possible. We collected most of the reproductive sexuals under stones covering the nest 
entrance. Because males and gynes do not differ in their tendency to escape collection our collection procedure probably provides a faithful picture of the different sex and castes produced by each colony (Keller et al. 1996). Samples (pupae and adults) of workers, males and gynes were stored at $-20{ }^{\circ} \mathrm{C}$ in $95 \%$ ethanol for subsequent genetic analyses. In the laboratory, the proportion of individuals belonging to each sex and caste was examined. Nine of 35 colonies collected produced less than 20 sexuals and were discarded from the analyses. Genetic analyses (see below) indicated that 10 colonies of 26 (i.e. 38\%) contained more than one queen (Fournier et al. 2002; Fournier et al. 2003). These polygynous colonies were used to determine reproductive skew and queen turnover. From the 10 polygynous colonies, we genotyped $18.9 \pm 3.5$ gynes (mean \pm SD), $4.4 \pm 6.4$ males, $18.0 \pm 4.2$ young workers and $17.0 \pm 2.8$ old workers per colony.

\section{Genetic analyses}

Four microsatellite loci (Ppal-03, Ppal-12, Ppal-83 and Ppal-19T; Fournier et al. 2002) were used to determine genotypes. The number of alleles and observed heterozygosity at these loci were estimated from worker genotype frequency data and ranged from 16 to 23 and from 0.69 to 0.93 , respectively. Ant DNA was extracted by homogenization of an entire individual in digestion solution (100 mm NaCl, $50 \mathrm{~mm}$ Tris, $1 \mathrm{~mm}$ EDTA, 0.5\% SDS, and $200 \mu \mathrm{g} / \mathrm{mL}$ proteinase $\mathrm{K}$ ) followed by digestion at $55^{\circ} \mathrm{C}$ for $2 \mathrm{~h}$ and extraction according to standard phenol/ chloroform protocol. The DNA was precipitated by sodium acetate $(3 \mathrm{M})$ in ethanol and suspended in $100 \mu \mathrm{L}$ of distilled water. Polymerase chain reactions (PCR) were carried out in a $10-\mu \mathrm{L}$ volume. Amplified fluorescent fragments were visualized on $5 \%$ polyacrylamide/ 6 m urea sequencing gels using an automated $377 \mathrm{ABI}$ sequencer.

Estimates of genetic relatedness $r$ among and between classes of colony members were calculated following the algorithm of Queller \& Goodnight (1989) (identityby-descent method) with the program RELATEDNESS 5.0.8. Colonies were weighted equally and standard errors were obtained by jackknifing over colonies. The minimum number of queens in each colony and their genotypes were inferred from the observed genotypes of workers at all loci (see Fournier et al. 2002 and Fournier et al. 2003 for details of the procedure). Maternity assignment was relatively simple as the number of queens per colony was fairly low (see Results) and because queens mate only once and males are haploid. The genotypes of all offspring were determined for at least three loci, which allowed us to assign offspring to specific mothers without any ambiguity, because nestmate queens are almost invariably unrelated and mate only once (Fournier et al. 2002; Fournier et al. 2003). The probability that related queens produce indistinguishable offspring was estimated conservatively as the probability that queens would mate with males carrying the same alleles at all loci (thus conservatively assuming that queens have the same genotype). This probability is the product of the sum of the squared allele frequencies (Pamilo 1993), and is equal to 0.0014 in our sample.

Queen replacement. Workers were subdivided into two age classes according to the developmental stage and/or degree of melanization. Pupae and recently eclosed workers with pale yellow colouration were classified as 'young workers', whereas adult workers with definitive dark colouration were classified as 'old workers'. Young workers developed from eggs laid in spring of the collection year (1999). Old workers represent earlier age cohorts and developed from eggs laid in spring/summer 1998, one year prior to collection.

The genetic effective turnover of queens $\tau$ was calculated from the genetic data following Pedersen \& Boomsma (1999; eqn 4, p. 906):

$\tau=1-\frac{r_{w w^{\prime}}}{r_{w}+r_{w^{\prime}}-r_{w w^{\prime}}}$

where $r_{w}$ represents the relatedness between old workers, $r_{w^{\prime}}$ the relatedness between young workers and $r_{w w}$ the relatedness between members of these two worker cohorts.

Reproductive skew. Reproductive skew within colonies was estimated with Nonacs' (2000) B index:

$B=\sum_{i=1}^{N}\left(p_{i}-\frac{n_{i}}{N_{t}}\right)^{2}-\left(1-\frac{1}{\bar{N}}\right) / K$

where $K$ is the total number of offspring, $p_{i}$ is the proportion of offspring produced by the $i$ th queen, $n_{i}$ is the time queen $i$ was present in a colony, and $N_{t}$ is the sum of the $n_{i}$ for the colony. $\bar{N}=N_{t} / n_{\max }$ is a weighted mean group size where $n_{\max }$ is the maximum time any queen could be present. Our study (see Results) revealed that queen turnover is very small in this population of $P$. pallidula. We therefore assumed that all queens were present the same length of time.

The $B$ index is equal to 0 for randomly distributed reproduction, positive when skew is greater than random and negative when skew is distributed more evenly than random. Reproductive skew was calculated using the program SKEW CALCULATOR 2002 developed by P. Nonacs (http://www.obee.ucla.edu/Faculty/Nonacs/). This program also allows estimation of the probability level for each group and across all groups that the observed $B$ values differ from zero (i.e. that reproduction is not randomly distributed between breeders). 


\section{Colony characteristics}

To test whether reproductive skew was correlated with colony productivity we estimated the biomass of sexuals produced by multiplying the number of sexuals by their relative dry weight (males: $W_{m}=0.88 \mathrm{mg} \pm 0.07$; females: $W_{f}=6.14 \mathrm{mg} \pm 1.44$; Keller et al. 1996).

\section{Statistical analyses}

Deviations of the variables from normality were tested using the Shapiro-Wilk test. When logarithmic or angular transformations did not suffice to normalize the data, we used nonparametric statistics. When a Levene's test did not give evidence for homoscedasticity, we used median test (Kasuya 2001). Tests for multiple comparisons were corrected with sequential Bonferroni adjustments of significance levels (Rice 1989). All statistical tests were two-tailed.

\section{Results}

The genetic analyses of the workers revealed that 10 colonies contained several reproductive queens (were polygynous) with six colonies containing two queens, two colonies containing three queens and two colonies containing four queens. Overall, the harmonic mean number of queens per colony was $N_{e, p}=2.40$. The mean effective numbers of queens estimated from young worker, gyne and male genotypes were 1.82, 1.95 and 1.06, respectively; Table 1. A one-way ANova revealed that these four estimates of queen numbers differed significantly (data were $\log$-transformed to correct for heteroscedasticity; $F_{3,30}=$

Table 1 Number of queens in each colony and overall colonies. $N_{e, p}$ is the harmonic mean number of queens, $N_{e, g g^{\prime}} N_{e, g m}$ and $N_{e, g w}$ are the effective number of queens weighted by the respective contribution of each queen to the production of gynes, males and workers, respectively

\begin{tabular}{llrrr}
\hline & \multicolumn{4}{l}{ Number of queens } \\
\cline { 2 - 5 } Colony number & $N_{e, p}$ & $N_{e, g g}$ & $N_{e, g m}$ & $N_{e, g w}$ \\
\hline B 99-1 & 2 & 1.80 & 1.41 & 1.68 \\
B 99-2 & 4 & 1.96 & 1.02 & 2.07 \\
B 99-7 & 2 & 2.09 & - & 1.34 \\
B 99-13 & 2 & 2.04 & - & 2.36 \\
B 99-15 & 2 & 1.37 & - & 1.47 \\
B 99-16 & 3 & 1.72 & 0.62 & 2.13 \\
B 99-27 & 3 & 3.64 & - & 2.97 \\
B 99-29 & 4 & 2.09 & - & 3.13 \\
B 99-31 & 2 & 2.14 & -14.07 & 1.78 \\
B 99-32 & 2 & 2.23 & 1.02 & 1.11 \\
Overall colonies & 2.40 & 1.95 & 1.06 & 1.82 \\
\hline
\end{tabular}

9.382, $P<0.001)$. A posteriori analyses indicated that the mean effective number of queens estimated from male production was significantly lower than the three other queen number estimates (Tukey tests, comparison with: young workers, $P=0.004$; gynes, $P=0.001$ and harmonic mean of the number of queens, $P<0.001$ ).

The examination of the pedigrees of old and young workers yielded similar - and not significantly different estimates of queen number (one-way ANOvA, $F_{1,18}=0.333$, $P=0.571$ ). Overall, the relatedness between young workers $\left(r_{w w w}=0.403 \pm 0.043\right)$ was similar to that of old workers $\left(r_{w^{\prime} w^{\prime}}=0.417 \pm 0.043\right)$. The relatedness between young and old workers was also comparable $\left(r_{w w^{\prime}}=0.407 \pm 0.039\right)$, the three values not being significantly different from each other (one-way ANova, $F_{2,27}=0.084, P=0.920$ ). The genetic effective turnover of queens was very low and equal to $\tau=$ $1.79 \%$ per year.

All average values of reproductive skew were greater than zero (Table 2). Overall, reproductive skew was significantly higher than expected under random reproduction for the production of gynes $(P<0.0001)$, males $(P<0.0001)$, sexuals (males + gynes $)(P<0.0001)$ as well as young worker production $(P<0.0001)$. In line with these results, we found that for the production of all classes of individuals the reproductive skew was significantly greater than expected under random reproduction in a notable proportion of colonies [gynes: five of 10 colonies; males: four of five colonies (no males were found in five colonies); sexuals: five of 10 colonies; young workers: four of 10 colonies; see Table 2].

A one-way ANOva revealed a significant difference between the estimates of reproductive skew for male, gyne and worker production $\left(F_{2,22}=11.964, P<0.001\right)$. A posteriori analyses showed that reproductive skew for male production was significantly greater than for the production of gynes as well as workers (Tukey tests, comparison with: gynes, $P<0.001$; young workers, $P=0.001$ ). By contrast, there was no significant difference between the reproductive skew for gyne and worker production $(P=0.991)$.

Multiple regressions indicated that the degree of reproductive skew for sexual productivity was not associated significantly with the number of queens nor overall colony productivity $\left(r=0.137 ; F_{2,7}=0.067, P=0.936\right)$. Similar results were obtained when skew was assessed separately for the production of gynes $\left(r=0.481 ; F_{2,7}=1.051, P=0.399\right)$, males $\left(r=0.931 ; F_{2,2}=6.504, P=0.133\right)$ and workers $(r=$ 0.193; $F_{2,7}=0.131, P=0.876$ ).

We obtained comparable results when the productivity was expressed per capita (per queen) instead of per colony. Multiple regressions showed no significant relationship between queen number, per capita productivity and skew for male production $\left(r=0.904 ; F_{2,2}=4.460, P=0.183\right)$, gyne production $\left(r=0.528 ; F_{2,7}=1.351, P=0.319\right)$, sexual production $\left(r=0.322 ; F_{2,7}=0.404, P=0.682\right)$ and worker 
Table 2 Number of queens, productivity and reproductive skew for the production of gynes, males, sexuals (gynes + males) and young workers in colonies of Pheidole pallidula. The observed reproductive skew values were tested for significant differences from zero, the expected value under random reproduction $\left({ }^{*} P<0.05 ;{ }^{* *} P<0.01\right.$; $\left.{ }^{* *} P<0.001\right)$

\begin{tabular}{|c|c|c|c|c|c|c|}
\hline \multirow[b]{2}{*}{ Colony number } & \multirow{2}{*}{$\begin{array}{l}\text { No. of } \\
\text { queens }\end{array}$} & \multirow{2}{*}{$\begin{array}{l}\text { Productivity } \\
(\mathrm{mg})\end{array}$} & \multicolumn{4}{|c|}{ Reproductive skew } \\
\hline & & & gynes & males & sexuals & young workers \\
\hline B 99-1 & 2 & 481.6 & $0.14^{*}$ & $0.25^{*}$ & -0.01 & 0.02 \\
\hline B 99-2 & 4 & 434.2 & 0.06 & $0.60^{* *}$ & $0.12^{* * *}$ & 0.02 \\
\hline B 99-7 & 2 & 147.4 & $0.10^{*}$ & - & $0.10^{*}$ & $0.22^{* *}$ \\
\hline B 99-13 & 2 & 128.9 & $0.14^{*}$ & - & $0.14^{*}$ & -0.03 \\
\hline B 99-15 & 2 & 203.5 & $0.20^{*}$ & - & 0.13 & -0.03 \\
\hline B 99-16 & 3 & 531.6 & $0.12^{*}$ & $0.50^{*}$ & $0.18^{* * *}$ & $0.18^{* * *}$ \\
\hline B $99-27$ & 3 & 270.2 & 0.02 & - & 0.02 & 0.05 \\
\hline В $99-29$ & 4 & 165.8 & -0.01 & - & -0.01 & $0.14^{* *}$ \\
\hline В $99-31$ & 2 & 599.1 & 0.10 & 0.38 & 0.01 & 0.03 \\
\hline B 99-32 & 2 & 535.7 & -0.05 & $0.14^{*}$ & $0.07^{*}$ & $0.30^{* * *}$ \\
\hline Overall colonies & $0.08^{* * *}$ & $0.37^{* * *}$ & $0.08^{* * *}$ & $0.09^{* * *}$ & & \\
\hline
\end{tabular}

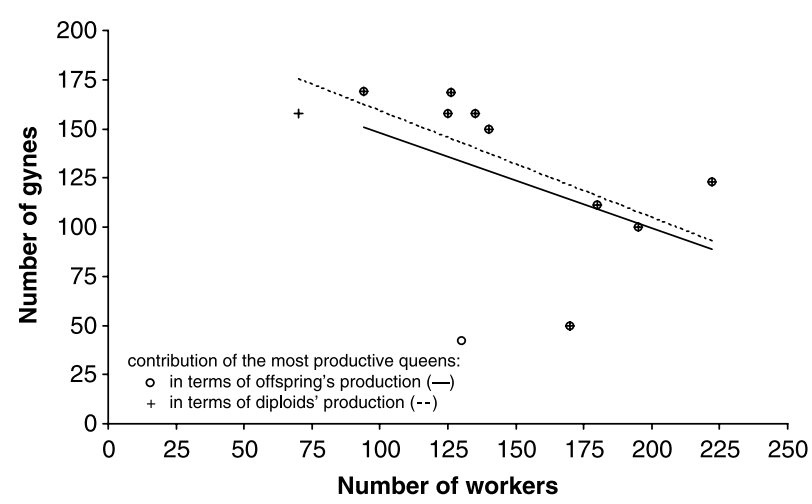

Fig. 1 Comparison of the relative contribution of the most productive queen to gyne and worker production (data are transformed to correct for the fact that the expected contribution of queens is lower in colonies with higher queen number).

production $\left(r=0.212 ; F_{2,7}=0.164, P=0.852\right)$. There was also no significant association between queen-queen relatedness and reproductive skew (Spearman's rank correlations, $P>0.05$ for all classes of individuals). However, it must be mentioned that only one colony contained related queens, thus resulting in a low power of this test.

The comparison of the relative contribution of queens to gyne and worker production revealed the existence of a trade-off between queens' contribution to reproductive and sterile females. The contribution of the most productive queen (i.e. the queen that produced the highest number of offspring, workers + gynes + males) to gyne production tended to be correlated negatively with her contribution to worker production (Spearman's rank correlation: $r=-0.608, n=10, P=0.062$; Fig. 1 ). The existence of a trade-off between gyne and worker production was confirmed when considering the contribution of queens to female production only. The contribution of the most productive queen to gyne production was again associated negatively with her contribution to worker production, the difference being significant in this case (Spearman's rank correlation: $r=-0.791, n=10, P=0.006$; Fig. 1). The tradeoff was also found at the colony level, with a significant difference between nestmate queens in their relative contribution to gyne and worker production in five of the 10 colonies ( $\chi^{2}$ tests, $P<0.05$ ). Over all colonies, such a tradeoff did not occur for the relative contribution of queens to male and gyne production (Spearman's rank correlation: $r=-0.152, n=6, P=0.774)$, male vs. worker production (Spearman's rank correlation: $r=-0.273, n=6, P=0.600$ ), and male vs. female (worker + gyne) production (Spearman's rank correlation: $r=-0.030, n=6, P=0.954$ ).

\section{Discussion}

Our genetic data showed that the queen turnover in P. pallidula is less than $2 \%$. This value is much lower than in Myrmica sulcinodis (Pedersen \& Boomsma 1999) and M. tahoensis (Evans 1996), the only two other ant species where turnover has been quantified on the basis of genetic relatedness. In M. sulcinodis, the comparison of worker cohorts separated by 1 year gave an effective turnover of queens of about $60 \%$. Indirect evidence suggests that such high rates of turnover might be common in other polygynous ants. Indeed, pedigree analyses showed high frequencies of colonies with incompatible genotypes between queens and adult workers (e.g. Seppä 1994; Bourke et al. 1997; Pearson et al. 1997). Several studies have also found that a high proportion of queens disappear each year (e.g. Linepithema humile, 90\%, Keller et al. 1989; Myrmica tahoensis, $35-50 \%$, Evans 1996). Finally, the finding that polygynous queens typically have a much shorter lifespan than 
monogynous queens (Keller \& Genoud 1997) with queens of many species having an average lifespan lower than $M$. sulcinodis queens (4-5 years; Elmes 1987) is consistent with the idea of high rates of queen turnover being common in polygynous ants. A possible explanation for the low queen turnover in $P$. pallidula is that in contrast to many polygynous species, nests are stable structures that go deep into the ground, thus possibly limiting queen mortality.

Our data revealed a significant reproductive skew for the production of all castes. Reproductive skew was significantly greater than expected under random reproduction for the production of gynes, males, sexuals (males + gynes) as well as young workers. However, reproductive skew was relatively low for gyne, worker and sexual production. The only relatively high value was observed for male production. Skew for male production was significantly higher than the skew for the production of the two female castes. In line with this finding, our data showed that the mean effective number of queens estimated from young worker and gyne genotypes were slightly lower, but not significantly so, than the harmonic queen number estimated by pedigree analyses. By contrast, the effective number of queens estimated from males was significantly lower than the harmonic queen number.

Skew has been measured in several other ant species, but only very few studies have compared reproductive skew for the production of gynes, males and workers. As in $P$. pallidula, there are significant differences in skew for gyne and worker parentage in the fire ant Solenopsis invicta (Ross 1988). The values for gyne and worker production are $B=$ $0.41 \pm 0.23(P<0.001)$ and $B=0.14 \pm 0.07(P<0.001)$, respectively (recalculated from data in Table 2, Ross 1988). Similarly, in the ant F. sanguinea, the mean relatedness among worker pupae was lower than among sexual female pupae, suggesting that a lower effective number of queens contribute to gyne than worker production (Pamilo \& Seppä 1994). A possible explanation for differences in skew for worker and gyne production is that in some species queens may bias the fate of their eggs, thus leading to differences between the relative contribution of nestmate queens to gyne and worker parentage.

The idea that female offspring produced by different queens may differ in the likelihood of developing into queens or workers is supported by our data showing a trade-off between the relative contribution of queens to workers and gynes. There are three mechanisms that may account for differences between queens in the likelihood of their female offspring developing into queens or workers.

The first is a genetic component to caste determination. So far, a strong genetic effect has been reported only in some Pogonomyrmex species (Helms-Cahan et al. 2002; Julian et al. 2002; Volny \& Gordon 2002) and it has been shown that this unusual system evolved following complex events of historical hybridization (Helms-Cahan \&
Keller 2003). A similar system of genetic caste determination is unlikely to be common in ants, where caste determination is primarily environmentally induced (Wheeler 1986; Hölldobler \& Wilson 1990). However, it is conceivable that the fate of larvae might be slightly influenced by genetic components, with some larvae being better able to manipulate the workers into rearing as sexuals than are others (Nonacs \& Tobin 1992). This has been studied only once in ants. In colonies of F. exsecta headed by queens mated with several males, there was no difference in the likelihood of female brood fathered by different males to develop into queens vs. workers, suggesting a lack of heritability for the process of caste determination (Keller et al. 1997). Thus, there is currently little support for the tradeoff between the relative contribution of queens to workers and gynes resulting from genetic differences between their offspring.

The second mechanism is a difference in the mean egglaying date of queens. In P. pallidula only eggs laid in early spring by queens that have hibernated can develop into female sexuals (Passera 1980). Thus, if nestmate queens differ in their relative contribution of eggs laid in early spring and later in the season (when all female eggs develop into workers), this may result in differences between queens in their relative apportionment of gynes and workers.

The third and somewhat related mechanism is maternal effects that are induced by hormones and/or other compounds transferred to the egg. Interestingly, evidence for such a maternal effect has been documented in P. pallidula. Physiological analyses have shown that variation in the juvenile hormone and ecdysterone levels of queens has a strong effect on whether a diploid egg will develop as a queen or a worker (Passera 1980; Suzzoni et al. 1980; Passera 1982). Thus, it is possible that nestmate queens lay different types of eggs with the effect that they contribute differently to the production of gynes and workers.

Our study revealed no evidence of a relationship between the relative contribution of queens to male and gyne production. Such a trade-off has been studied in only one other social insect, the Argentine ant Linepithema humile. In this species there was a negative relationship between a queen contribution to male and gyne production in twoqueen colonies (Fournier \& Keller 2001). Possibly, this stems from queens differing in the proportion of male and female eggs produced, although a previous study failed to reveal such a difference in $P$. pallidula (Keller et al. 1996).

Finally, our study also revealed no evidence that reproductive skew was associated with the colony social attributes measured in this study. Skew was not associated significantly with the number of queens, overall colony productivity or per-queen productivity. This lack of association was true whether skew was measured for the production of gynes, males, all sexuals or young workers. We also found no evidence for an association between skew 
and queen-queen relatedness. However, it is important to note that queens were related in only one of the 10 colonies sampled. Thus, our study had little power to detect any association between skew and queen-queen relatedness. Finally, the number of potential breeders has been proposed as being a possible factor influencing skew (Johnstone et al. 1999; Reeve \& Emlen 2000). Ours is the first study testing the relationship between the number of group breeders and the extent of reproductive skew; however, we found no significant relationship between the number of queens per colony and reproductive skew.

In conclusion, this study shows a significant reproductive skew for the production of each caste and sex. Importantly, it reveals for the first time a trade-off between the relative contribution of queens to gyne and worker production. Indirect evidence suggests that such a trade-off occurs possibly in other ants and might be more common than generally realized. In any case, this study reveals that it is necessary to quantify the contribution of queens to the production of each caste and sex to assess their relative reproductive success and understand the mechanisms influencing reproductive skew.

\section{Acknowledgements}

We thank Rob Hammond, Jes Pedersen, Karen Parker, Cédric Devigne and four referees for their comments on the manuscript. This work was supported by grants from the Belgian Fonds National de la Recherche Scientifique, the Fonds Defay, the Banque Nationale de Belgique, the University of Brussels (SA), the Fondation de Meurs-François (DF), the Fondation Van Buuren (DF) and the Swiss National Science Foundation.

\section{References}

Bontpart H (1964) Recherches préliminaires sur la biologie de Pheidole pallidula Nyl. (Hyménoptère Formicoidea Myrmicidae). PhD Thesis, Université de Toulouse - Faculté des Sciences, France.

Bourke AFG, Green HAA, Bruford MW (1997) Parentage, reproductive skew and queen turnover in a multiple-queen ant analysed with microsatellites. Proceedings of the Royal Society of London, Series B, 264, 277-283.

Bourke AFG, Heinze J (1994) The ecology of communal breeding: the case of multiple-queen leptothoracine ants. Philosophical Transactions of the Royal Society of London, Series B, 345, 359-372.

Elmes GW (1987) Temporal variation in colony populations of the ant Myrmica sulcinodis. I. Changes in queen number, worker number and spring production. Journal of Animal Ecology, 56, $559-571$.

Emlen ST (1982a) The evolution of helping. I. An ecological constraints model. American Naturalist, 119, 29-39.

Emlen ST (1982b) The evolution of helping. II. The role of behavioral conflict. American Naturalist, 119, 40-53.

Evans JD (1996) Queen longevity, queen adoption, and posthumous indirect fitness in the facultatively polygynous ant Myrmica tahoensis. Behavioral Ecology and Sociobiology, 39, 275284.
Fournier D, Aron S, Milinkovitch MC (2002) Investigation of the population genetic structure and mating system in the ant Pheidole pallidula. Molecular Ecology, 11, 1805-1814.

Fournier D, Keller L (2001) Partitioning of reproduction among queens in the Argentine ant, Linepithema humile. Animal Behaviour, 62, 1039-1045.

Fournier D, Keller L, Passera L, Aron S (2003) Colony sex ratios vary with breeding system but not relatedness asymmetry in the facultatively polygynous ant Pheidole pallidula. Evolution, 57, $1336-1342$.

Hannonen M, Sundström L (2002) Proximate determinants of reproductive skew in polygyne colonies of the ant Formica fusca. Ethology, 108, 961-973.

Hannonen M, Sundström L (2003) Worker nepotism among polygynous ants. Nature, 421, 910.

Heinze J, Keller L (2000) Alternative reproductive strategies: a queen perspective in ants. Trends in Ecology and Evolution, 15, $508-512$.

Heinze J, Trunzer B, Hölldobler B, Delabie JHC (2001) Reproductive skew and queen relatedness in an ant with primary polygyny. Insectes Sociaux, 48, 149-153.

Helms-Cahan S, Parker JD, Rissing SW et al. (2002) Extreme genetic differences between queens and workers in hybridizing Pogonomyrmex harvester ants. Proceedings of the Royal Society of London, Series B, 269, 1871-1877.

Helms-Cahan S, Keller L (2003) Complex hybrid origin of genetic caste determination in harvester ants. Nature, 424, 306-309.

Hölldobler B, Wilson EO (1990) The Ants. Springer-Verlag, Berlin. Johnstone RA (2000) Models of reproductive skew: a review and synthesis. Ethology, 106, 5-26.

Johnstone RA, Cant MA (1999) Reproductive skew and the threat of eviction: a new perspective. Proceedings of the Royal Society of London, Series B, 266, 275-279.

Johnstone RA, Woodroffe R, Cant MA, Wright J (1999) Reproductive skew in multimember groups. American Naturalist, 153, 315-331.

Julian GE, Fewell JH, Gadau J, Johnson RA, Larrabee D (2002) Genetic determination of the queen caste in an ant hybrid zone. Proceedings of the National Academy of Sciences, USA, 99, $8157-8160$.

Kasuya E (2001) Mann-Whitney $U$ test when variances are unequal. Animal Behaviour, 61, 1247-1249.

Keller L (1993a) The assessment of reproductive success of queens in ants and other social insects. Oikos, 67, 177-180.

Keller L (1997) Indiscriminate altruism: unduly nice parents and siblings. Trends in Ecology and Evolution, 12, 99-103.

Keller L, ed. (1993b) Queen Number and Sociality in Insects. Oxford University Press, Oxford.

Keller L, Aron S, Passera L (1996) Internest sex-ratio variation and male brood survival in the ant Pheidole pallidula. Behavioral Ecology, 7, 292-298.

Keller L, Genoud M (1997) Extraordinary lifespans in ants: a test of evolutionary theories of ageing. Nature, 389, 958-960.

Keller L, Passera L, Suzzoni J-P (1989) Queen execution in the Argentine ant, Iridomyrmex humilis. Physiological Entomology, 14, 157-163.

Keller L, Reeve HK (1994) Partitioning of reproduction in animal societies. Trends in Ecology and Evolution, 9, 98-102.

Keller L, Sundström L, Chapuisat M (1997) Male reproductive success: paternity contribution to queens and workers in Formica ants. Behavioral Ecology and Sociobiology, 41, 11-15. 
Nonacs P (2000) Measuring and using skew in the study of social behavior and evolution. American Naturalist, 156, 577-589.

Nonacs P, Tobin JE (1992) Selfish larvae: development and the evolution of parasitic behavior in the Hymenoptera. Evolution, 46, 1605-1620.

Pamilo P (1993) Polyandry and allele frequency differences between the sexes in the ant Formica aquilonia. Heredity, 70, 472480.

Pamilo P, Seppä P (1994) Reproductive competition and conflicts in colonies of the ant Formica sanguinea. Animal Behaviour, 48, 1201-1206.

Passera L (1978) Une nouvelle catégorie d'oeufs alimentaires: les oeufs alimentaires émis par les reines vierges de Pheidole pallidula (Nyl.) (Formicidae, Myrmicinae). Insectes Sociaux, 25, 117-126.

Passera L (1980) La ponte d'oeufs préorientés chez la fourmi Pheidole pallidula (Nyl.) (Hymenoptera - Formicidae). Insectes Sociaux, 27, 79-95.

Passera L (1982) Endocrine regulation of caste determination in ants. In: Social Insects in the Tropics. Proceedings of the First International Symposium (ed. Jaisson P), pp. 41-62. Presses de l'Université Paris XIII, Paris.

Pearson B, Raybould AF, Clarke RT (1997) Temporal changes in the relationship between observed and expected sex-investment frequencies, social structure and intraspecific parasitism in Leptothorax tuberum (Formicidae). Biological Journal of the Linnean Society, 61, 515-536.

Pedersen JS, Boomsma JJ (1999) Effect of habitat saturation on the number and turnover of queens in the polygynous ant, Myrmica sulcinodis. Journal of Evolutionary Biology, 12, 903-917.

Queller DC, Goodnight KF (1989) Estimating relatedness using genetic markers. Evolution, 43, 258-275.

Ragsdale JE (1999) Reproductive skew theory extended: the effect of resource inheritance on social organization. Evolutionary Ecology Research, 1, 859-874.

Reeve HK (1998) Game theory, reproductive skew, and nepotism. In: Game Theory and Animal Behavior (eds Dugatkin LA, Reeve HK), pp. 118-145. Oxford University Press, New York.

Reeve HK, Starks PT, Peters JM, Nonacs P (2000) Genetic support for the evolutionary theory of reproductive transactions in social wasps. Proceedings of the Royal Society of London, Series B, 267, 75-79.

Reeve HK, Emlen ST (2000) Reproductive skew and group size: an $\mathrm{N}$-person staying incentive model. Behavioral Ecology, 11, 640647.

Reeve HK, Emlen ST, Keller L (1998) Reproductive sharing in animal societies: reproductive incentives or incomplete control by dominant breeders? Behavioral Ecology, 9, 267-278.
Reeve HK, Keller L (1995) Partitioning of reproduction in motherdaughter versus sibling associations: a test of optimal skew theory. American Naturalist, 145, 118-132.

Reeve HK, Keller L (1997) Reproductive bribing and policing as evolutionary mechanisms for the supression of within-group selfishness. American Naturalist, 150, S42-S58.

Reeve HK, Keller L (2001) Tests of reproductive-skew models in social insects. Annual Review of Entomology, 46, 347-385.

Reeve HK, Ratnieks FLW (1993) Queen-queen conflicts in polygynous societies: mutual tolerance and reproductive skew. In: Queen Number and Sociality in Insects (ed. Keller L), pp. 45-85. Oxford University Press, Oxford.

Rice WR (1989) Analyzing tables of statistical tests. Evolution, 43, 223-225.

Ross KG (1988) Differential reproduction in multiple-queen colonies of the fire ant Solenopsis invicta (Hymenoptera: Formicidae). Behavioral Ecology and Sociobiology, 23, 341-355.

Rüppell O, Heinze J, Hölldobler B (2002) Intracolonial patterns of reproduction in the queen-size dimorphic ant Leptothorax rugatulus. Behavioral Ecology, 13, 239-247.

Seppä P (1994) Sociogenetic organization of the ants Myrmica ruginodis and Myrmica lobicornis: number, relatedness and longevity of reproducing individuals. Journal of Evolutionary Biology, 7, 71-95.

Suzzoni J-P, Passera L, Strambi A (1980) Ecdysteroid titre and caste determination in the ant, Pheidole pallidula (Nyl.) (Hymenoptera: Formicidae). Experientia, 36, 1228-1229.

Vehrencamp SL (1983a) A model for the evolution of despotic versus egalitarian societies. Animal Behaviour, 31, 667-682.

Vehrencamp SL (1983b) Optimal degree of skew in cooperative societies. American Zoologist, 23, 327-335.

Volny VP, Gordon DM (2002) Genetic basis for queen-worker dimorphism in a social insect. Proceedings of the National Academy of Sciences, USA, 99, 6108-6111.

Wheeler DE (1986) Developmental and physiological determinants of caste in social Hymenoptera: evolutionary implications. American Naturalist, 128, 13-34.

This work was part of Denis Fournier's doctoral thesis on population genetics, mating systems and social conflicts in ants. Serge Aron is Senior Research Associate of the Belgian FNRS and works on kin conflicts and sex ratio determination in several ant species. Laurent Keller is Professor and head of the Department of Ecology and Evolution at the University of Lausanne. He works on various aspects of evolutionary ecology such as reproductive skew, sex allocation, caste determination and the molecular basis of ageing in social insects. 